\title{
ПЛАНИРОВАНИЕ СЕБЕСТОИМОСТИ УСЛУГ В ЖИЛИЩНО-КОММУНАЛЬНОЙ ОТРАСЛИ В УСЛОВИЯХ ПОВЫШЕННОЙ ГОТОВНОСТИ
}

\author{
(c) 2020 Шлычков Дмитрий Сергеевич \\ кандидат экономических наук, доцент Департамента учета, анализа и аудита \\ Финансовый университет при Правительстве Российской Федерации, Россия, Москва \\ E-mail: sds457@mail.ru
}

Калькулирование себестоимости товаров (работ, услуг) это один из важных стратегических участков в финансово-производственной деятельности экономического субъекта. В ряде отраслей экономики определение себестоимости жестко соотносится с производственным процессом и нормами расхода ресурсов на производство продукции. Калькулирование услуг является более гибким процессом при этом на формирование стоимости услуги может повлиять внешний фактор - стоимость услуги на рынке аналогичных услуг у конкурентов. В статье рассмотрено формирование стоимости услуг в жилищно-коммунальной отрасли экономики. Процесс расчета и калькулирования в частности жилищной услуги определен в три этапа: планирование, бюджетирование, калькулирование, что и определило основным результатом исследования. Кроме того, выше названные этапы были применимы при построении цепочки ценностей по Портеру.

Ключевые слова: планирование, бюджетирование, калькулирование, жилищная услуга, цепочка ценностей.

Такая отрасль экономики как жилищнокоммунальное хозяйство является одной из стратегически важных сфер деятельности государства любой страны. Это вызвано тем, что жилищно-коммунальное хозяйство обеспечивает жизнедеятельность населения в первую очередь, а также промышленности.

Основным нормативно-правовым документом является Жилищный кодекс Российской Федерации. Данный Кодекс регулирует права человека на владение и пользование принадлежащих ему помещений на праве собственности или хозяйственном ведении. Кроме того, имеются подзаконные акты, регулирующие различные правовые положения - права и обязанности собственника на владение и содержание помещений.

Любое здание независимо от его статуса жилое или нежилое должно быть должным образом обеспечено наблюдением в части его содержания. Функцию текущего содержания жилых и нежилых зданий несет собственник, однако данную функцию он может передать экономическому субъекту - Обществу, осуществляющему управление на договорной основе недвижимым имуществом. Говоря об управлении многоквартирными домами можно выделить следующие основные категории экономических субъектов: товарищество собственников жилья и управляющие компании. Принцип формирования стоимости оказываемых услуг по управлению многоквартирным домом един для всех категорий экономических субъектов - обеспечение комфортного проживания граждан в многоквартирном доме.

Планирование себестоимости услуги по текущему содержанию многоквартирного дома должно осуществляться исходя из следующих критериев, которые определять прямые затраты:

- этажность дома,

- технические и инженерные характеристики дома,

- благоустройство территории дома.

Производя расчет и планирование себестоимости услуг необходимо руководствоваться следующими законодательными актами:

1. Постановление Правительства РФ от 06.05.2011 № 354 (ред. от 13.07.2019, с изм. от 02.04.2020) «О предоставлении коммунальных услуг собственникам и пользователям помещений в многоквартирных домах и жилых домов» (вместе с «Правилами предоставления коммунальных услуг собственникам и пользователям помещений в многоквартирных домах и жилых домов») 
2. Постановление Правительства РФ от 13.08.2006 № 491 (ред. от 23.11.2019) «Об утверждении Правил содержания общего имущества в многоквартирном доме и правил изменения размера платы за содержание жилого помещения в случае оказания услуг и выполнения работ по управлению, содержанию и ремонту общего имущества в многоквартирном доме ненадлежащего качества и (или) с перерывами, превышающими установленную продолжительность»

3. Постановление Правительства РФ от 03.04.2013 № 290 (ред. от 15.12.2018) «О минимальном перечне услуг и работ, необходимых для обеспечения надлежащего содержания общего имущества в многоквартирном доме, и порядке их оказания и выполнения» (вместе с «Правилами оказания услуг и выполнения работ, необходимых для обеспечения надлежащего содержания общего имущества в многоквартирном доме»)

4. Приказ Минфина России от 06.05.1999 № 33н (ред. от 06.04.2015) «Об утверждении Положения по бухгалтерскому учету «Расходы организации» ПБУ 10/99»

Для определения стоимости оказания услуг по управлению многоквартирным домом устанавливается следующая последовательность расчетных процессов: планирование (в том числе планирование ресурсов экономического субъекта), бюджетирование, калькулирование.

Планирование - определение целей и формулирование, оценка и выбор политики, стратегии, тактики и действий, необходимых для их достижения.

Планирование ресурсов экономического субъекта - стратегический инструмент, обычно базирующийся на использовании программного обеспечения, позволяющий интегрировать все бизнес-процессы и обеспечивать возможность интеграции и синхронизации изолированных функций предприятия по всей стоимостной цепочке, тем самым создавая упорядоченные процессы, которые могут способствовать достижению конкурентных преимуществ.

Основываясь на Постановлении Правительства РФ № 290 формируются типовой перечень расходов на управление многоквартирным домом которые в свою очередь определяют прямые затраты на дом (табл. 1).

Кроме прямых затрат, отраженных в табли-

Таблица 1. Группы расходов по управлению многоквартирным домом.

\begin{tabular}{|c|c|}
\hline $\begin{array}{c}\text { Группа } \\
\text { расходов }\end{array}$ & Виды расходов \\
\hline 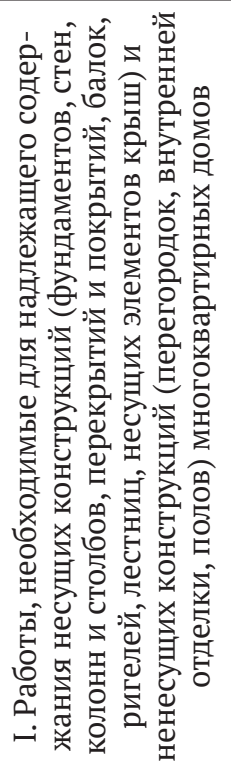 & $\begin{array}{l}\text { 1. Работы, выполняемые в отношении всех видов фундаментов } \\
\text { 2. Работы, выполняемые в зданиях с подвалами } \\
\text { 3. Работы, выполняемые для надлежащего содержания стен многоквартирных домов } \\
\text { 4. Работы, выполняемые в целях надлежащего содержания перекрытий и покрытий много- } \\
\text { квартирных домов } \\
\text { 5. Работы, выполняемые в целях надлежащего содержания колонн и столбов многоквартир- } \\
\text { ных домов } \\
\text { 6. Работы, выполняемые в целях надлежащего содержания балок (ригелей) перекрытий и } \\
\text { покрытий многоквартирных домов } \\
\text { 7. Работы, выполняемые в целях надлежащего содержания крыш многоквартирных домов } \\
\text { 8. Работы, выполняемые в целях надлежащего содержания лестниц многоквартирных } \\
\text { домов } \\
\text { 9. Работы, выполняемые в целях надлежащего содержания фасадов многоквартирных } \\
\text { домов } \\
\text { 10. Работы, выполняемые в целях надлежащего содержания перегородок в многоквартир- } \\
\text { ных домах } \\
\text { 11. Работы, выполняемые в целях надлежащего содержания внутренней отделки много- } \\
\text { квартирных домов,- проверка состояния внутренней отделки. 12. Работы, выполняемые } \\
\text { в целях надлежащего содержания полов помещений, относящихс к общему имуществу в } \\
\text { многоквартирном доме } \\
\text { 13. Работы, выполняемые в целях надлежащего содержания оконных и дверных заполне- } \\
\text { ний помещений, относящихся к общему имуществу в многоквартирном доме: }\end{array}$ \\
\hline
\end{tabular}




\begin{tabular}{|c|c|}
\hline 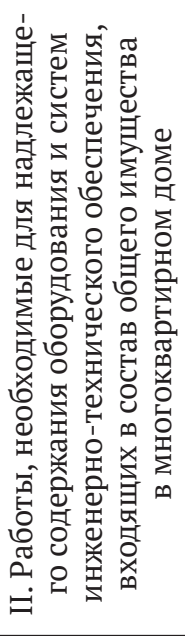 & $\begin{array}{l}\text { 14. Работы, выполняемые в целях надлежащего содержания мусоропроводов многоквар- } \\
\text { тирных домов } \\
\text { 15. Работы, выполняемые в целях надлежащего содержания систем вентиляции и дымоуда- } \\
\text { ления многоквартирных домов } \\
\text { 16. Работы, выполняемые в целях надлежащего содержания печей, каминов и очагов в } \\
\text { многоквартирных домах } \\
\text { 17. Работы, выполняемые в целях надлежащего содержания индивидуальных тепловых } \\
\text { пунктов и водоподкачек в многоквартирных домах } \\
\text { 18. Общие работы, выполняемые для надлежащего содержания систем водоснабжения (хо- } \\
\text { лодного и горячего), отопления и водоотведения в многоквартирных домах } \\
\text { 19. Работы, выполняемые в целях надлежащего содержания систем теплоснабжения (ото- } \\
\text { пление, горячее водоснабжение) в многоквартирных домах } \\
\text { 20. Работы, выполняемые в целях надлежащего содержания электрооборудования, радио- и } \\
\text { телекоммуникационного оборудования в многоквартирном доме } \\
\text { 21. Работы, выполняемые в целях надлежащего содержания систем внутридомового газо- } \\
\text { вого оборудования в многоквартирном доме } \\
\text { 22. Работы, выполняемые в целях надлежащего содержания и ремонта лифта (лифтов) в } \\
\text { многоквартирном доме }\end{array}$ \\
\hline 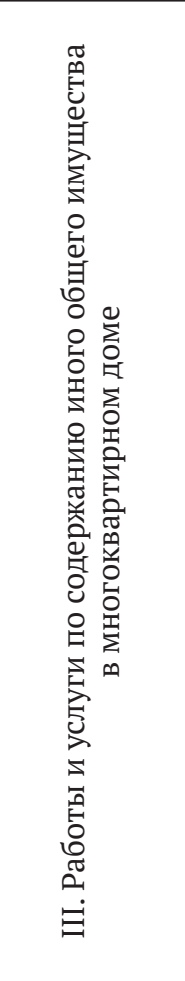 & $\begin{array}{l}\text { 23. Работы по содержанию помещений, входящих в состав общего имущества в многоквар- } \\
\text { тирном доме } \\
\text { 24. Работы по содержанию земельного участка, на котором расположен многоквартирный } \\
\text { дом, с элементами озеленения и благоустройства, иными объектами, предназначенными } \\
\text { для обслуживания и эксплуатации этого дома (далее - придомовая территория), в холод- } \\
\text { ный период года } \\
\text { 25. Работы по содержанию придомовой территории в теплый период года } \\
\text { 26. Работы по обеспечению вывоза, в том числе откачке, жидких бытовых отходов } \\
\text { 26(1). Работы по организации и содержанию мест (площадок) накопления твердых ком- } \\
\text { мунальных отходов, включая обслуживание и очистку мусоропроводов, мусороприемных } \\
\text { камер, контейнерных площадок. } \\
\text { 26(2). Организация накопления отходов I-IV классов опасности (отработанных ртутьсо- } \\
\text { держащих ламп и др.) и их передача в организации, имеющие лицензии на осуществление } \\
\text { деятельности по сбору, транспортированию, обработке, утилизации, обезвреживанию, } \\
\text { размещению таких отходов. } \\
\text { 27. Работы по обеспечению требований пожарной безопасности - осмотры и обеспечение } \\
\text { работоспособного состояния пожарных лестниц, лазов, проходов, выходов, систем ава- } \\
\text { рийного освещения, пожаротушения, сигнализации, противопожарного водоснабжения, } \\
\text { средств противопожарной защиты, противодымной защиты. } \\
\text { 28. Обеспечение устранения аварий в соответстви с установленными предельными срока- } \\
\text { ми на внутридомовых инженерных системах в многоквартирном доме, выполнения заявок } \\
\text { населения. } \\
\text { 29. Проверка состояния и при необходимости выполнение работ по восстановлению кон- } \\
\text { струкций и (или) иного оборудования, предназначенного для обеспечения условий доступ- } \\
\text { ности для инвалидов помещения многоквартирного дома. } \\
\text { з0. Работы и услуги, предусмотренные разделами І и II перечня, которые могут повлиять } \\
\text { на обеспечение условий доступности для инвалидов помещения многоквартирного дома, } \\
\text { выполняются с учетом обеспечения такого доступа }\end{array}$ \\
\hline
\end{tabular}

це 1 необходимо при планировании учитывать и накладные расходы - цеховые и общеэксплуатационные.

Цеховые и общеэксплуатационные расходы включают затраты, связанные с управлением и содержанием отдельных служб и подразделений организации в целом. Это оплата труда цехового и административно - управленческого персо- нала с отчислениями на социальное страхование, затраты на оплату консультационных услуг, командировок и представительских расходов, амортизация основных средств общецехового и общеэксплуатационного назначения, их ремонт и техническое обслуживание и др.

Эти затраты являются условно - постоянными и в случае сокращения объема реализации 
услуг их величина в расчете на себестоимость единицы услуги, увеличивается.

Планирование цеховых и общеэксплуатационных расходов осуществляется на основе анализа фактических данных, их динамики за ряд лет и намечаемых в планируемом периоде изменений.

Следующий этап в цепочке расчета себестоимости услуг жилищно-коммунальной отрасли является процесс бюджетирования.

Бюджетирование - бизнес-процесс реализации стратегии экономического субъекта, основанный на утвержденных плановых ресурсах по средствам составления экономических бюджетов (смет).

Бюджет (смета) - экономический элемент системы бюджетирования отражающий экономическую составляющую планового ресурса виде внутреннего документа организации содержащий количественные показатели в натуральном и денежном выражении объектов бухгалтерского учета (активы, обязательства, доходы, расходы, денежные потоки).

Бюджетирование как единый процесс составления бюджетов может быть организован с использованием различных стратегических подходов:

- бюджетирование «сверху-вниз» или «снизу-вверх»;

- дополнительное бюджетирование;

- нулевое бюджетирование;

- бюджетирование программ;

- бюджетирование с маркетинговой проверкой.

Рассматривая вышеперечисленные подходы возможность их применения в той или иной мере в жилищно-коммунальной отрасли имеет место быть. Однако данные подходы не отражают полную реализацию стратегии экономического субъекта. В данной отрасли достаточно полно отражает подход системы бюджетирования - бюджетирование на основе приоритетов. Метод бюджетирования, в соответствии с которым к бюджетным заявкам прилагается описание изменений, которые произойдут, если показатели бюджета предыдущего периода увеличить или уменьшить на определенную сумму или процент. Эти изменения принимаются в качестве приоритетных. Кроме того, необходимо при составлении бюджетов (смет) применять такой прием как бюджетный резерв, который отражает намеренное завышение расходов и/ или занижение доходов в бюджетном процессе.

Бюджетный резерв может быть основан на одном из следующих показателей:

- утвержденный уровень оплаты жилищнокоммунальных услуг по субъекту Российской Федерации;

- статистические данные по задолженности населения за коммунальные услуги по субъекту Российской Федерации;

- фактический уровень задолженности по каждому объекту жилищного фонда экономического субъекта за прошедший финансовый период.

Первые два показателя являются усредненными, но при этом открытыми для заинтересованных пользователей. Третий показатель объективен и показывает фактический уровень оплаты населением услуг за потребленные ими ресурсы.

Бюджетный процесс объединяет в себе ряд индивидуально экономически направленных бюджетов. В общем виде бюджетный процесс можно представить в следующем виде (рис. 1).

Следующим заключительным этапом расчета себестоимости жилищной услуги является этап калькулирования.

Калькулирование - формирование специальной информационной системы учетных данных для обеспечения процесса исчисления прошлой и будущей себестоимости.

Традиционно калькулирование должно охватывать три составляющие затрат: прямые, накладные, непроизводственные.

Прямые затраты должны отражать экономически обоснованный уровень требуемых расходов на содержание и эксплуатацию дома, то есть в прямые затраты включаются расходы согласно минимальному перечню оказываемых услуг. По согласованию с собственниками данный перечень может быть расширен.

Накладные затраты (общеэксплуатационные расходы) определяют административный ресурс экономического субъекта.

K непроизводственным затратам (внеобщеэксплуатационные расходы) можно отнести бюджетный резерв или уровень дебиторской задолженности.

Примерный перечень калькуляционных статей определяющие себестоимость жилищной ус- 


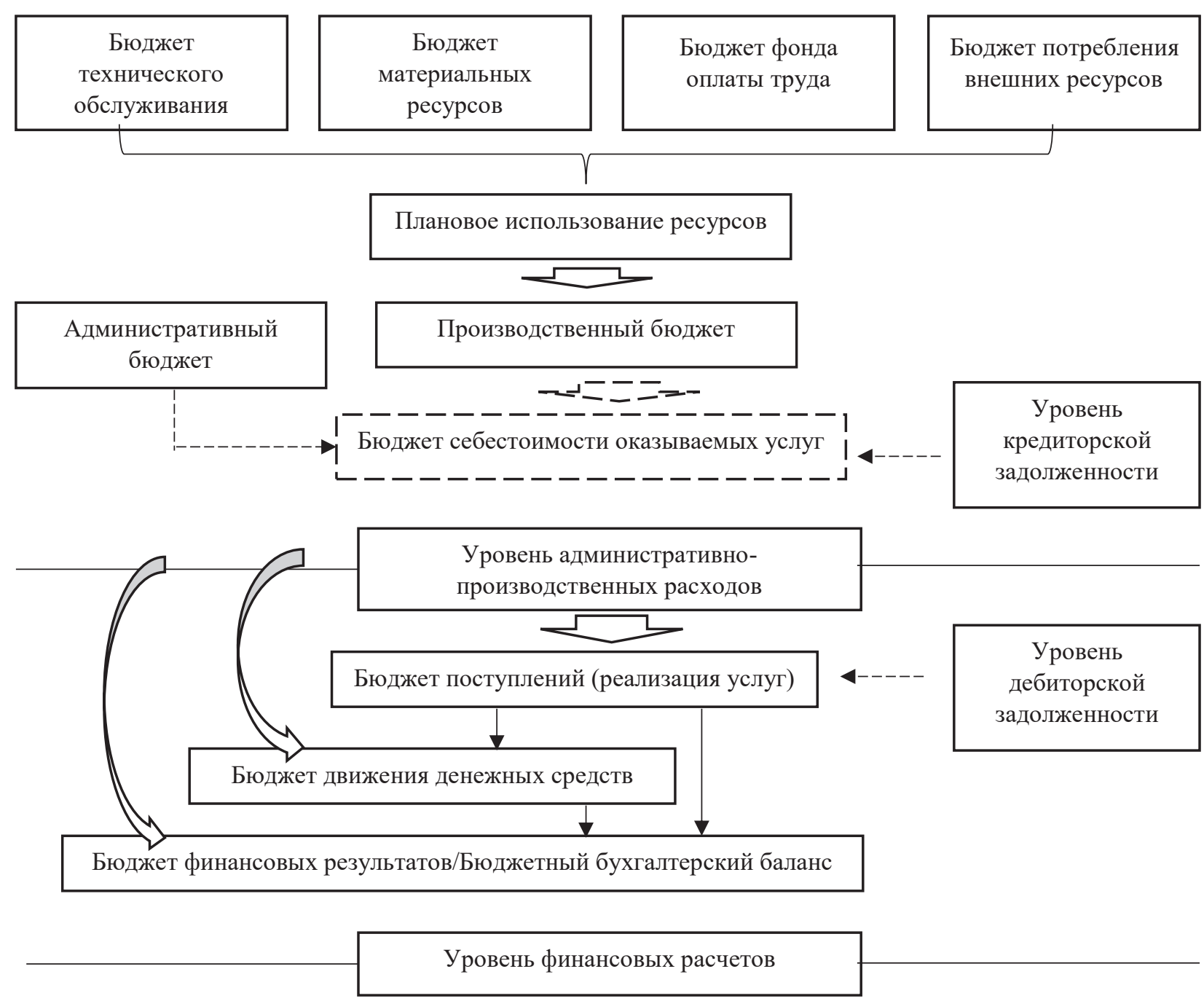

Puc. 1. Модель бюджетного процесса экономического субъекта, оказывающего жилищные услуги

луги включает:

1. Содержание и ремонт конструктивных элементов жилых зданий:

1.1. Заработная плата рабочих

1.2. Отчисления на социальные нужды

1.3. Материальные затраты

1.4. Услуги сторонних организаций

1.5. Прочие расходы

2. Содержание и ремонт внутридомового инженерного оборудования:

2.1. Заработная плата рабочих

2.2. Отчисления на социальные нужды

2.3. Материальные затраты

2.4. Услуги сторонних организаций
2.5. Прочие расходы

3. Благоустройство и обеспечение санитарного состояния жилых зданий и придомовой территории:

3.1. Заработная плата рабочих

3.2. Отчисления на социальные нужды

3.3. Материальные затраты

3.4. Услуги сторонних организаций

3.5. Прочие расходы

4. Общеэксплуатационные расходы

5. Внеэксплуатационные расходы

6. Полная себестоимость содержания 1 кв. м. общей площади жилых/нежилых помещений (стр. $1+$ стр. 2 + стр. 3 + стр. 4 + стр. 5 ) 


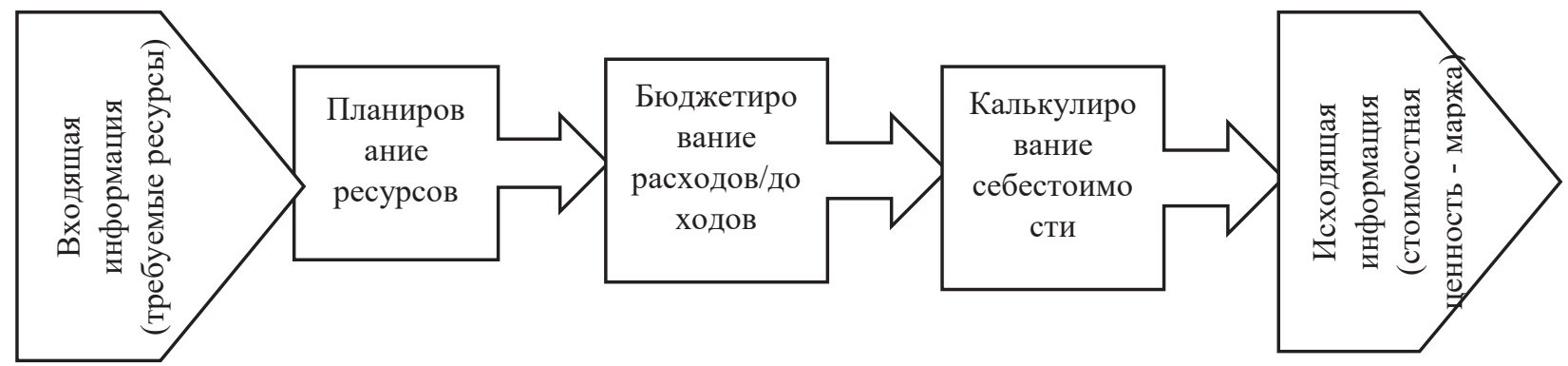

Puc. 2. Цепочка ценностей формирования себестоимости жилищной услуги по Портеру

В современных условиях хозяйствования организациям жилищно-коммунальной отрасли основную финансовую поддержку могут обеспечить внеэксплуатационные расходы или как выше сказано бюджетный резерв.

Обоснованность данного резерва заключается в том, что экономический субъект с одной стороны покрывает текущие расходы в достаточно полном объеме, в котором требует законодательство, с другой стороны при взыскания денежных средств и их поступлениях в будущих периодах у организации образуется высоколиквидные активы.

В современных условиях хозяйствования и влияния внешних факторов приводит к тому что экономическому субъекту требуется дополнительные расходы на реализацию оперативных мероприятий, что на практике показало распространения COVID-19. Не имея запаса финансовой прочности организациям жилищной сферы пришлось сократить расходы, например, по благоустройству территории и направить их на увеличение расходов по дезинфекции мест общего пользования дома. В том случае, когда в себестоимость заложен уровень дебиторской задолженности организация таким образом определяет на будущие периоды запас финансовой прочности в виде поступлений высоколиквидных активов - денежных средств за оказанные услуги населению, что положительно может повлиять на реализацию оперативных мероприятий требующих комфортного проживания собственников многоквартирного дома.

При реализации стратегии управления многоквартирным домом и определения себестоимости оказываемых услуг экономическому субъекту требуется применить на практике цепочку ценностей по Портеру.

Реализация цепочки ценности при определении себестоимости жилищной услуги как определено выше будет состоять из трех основных звеньев (рис. 2).

Таким образом реализация стратегических подходов в работе организаций жилищной сферы позволит усилить финансовую прочность и реализовать главную направленность своей деятельности - комфортное проживание собственников помещений в многоквартирном доме.

\section{Библиографический список}

1. Постановление Правительства РФ от 03.04.2013 № 290 (ред. от 15.12.2018) «О минимальном перечне услуг и работ, необходимых для обеспечения надлежащего содержания общего имущества в многоквартирном доме, и порядке их оказания и выполнения» (вместе с «Правилами оказания услуг и выполнения работ, необходимых для обеспечения надлежащего содержания общего имущества в многоквартирном доме»)

2. Коробко В.И. Экономика многоквартирного дома: учеб. пособие для студентов вузов, обучающихся по специальностям «Менеджмент организаций», «Государственное и муниципальное управление» / В.И. Коробко.- М.: ЮНИТИ-ДАНА, 2015.- 303 с.

3. Николаева О.Е., Алексеева О.В. Стратегический управленческий учет.- М.: Едиториал УРСС, 2003. - 304 с. 
4. Райан Б. Стратегический учет для руководителя / Пер. с англ. под ред. В. А. Микрюкова. - .: Аудит, ЮНИТИ, 1998.- 616 c.

5. Управленческий учет: официальная терминология СІМА / Пер. с англ. О.Е.Николаевой, Т. В.Шишковой.М.: ИД ФКБ-ПРЕСС, 2004.-200 с. 